NASA/CR—2005-213817

\title{
Identification of Noise Sources in High Speed Jets via Correlation Measurements-A Review
}

Jayanta Panda

Ohio Aerospace Institute, Brook Park, Ohio 
Since its founding, NASA has been dedicated to the advancement of aeronautics and space science. The NASA Scientific and Technical Information (STI) Program Office plays a key part in helping NASA maintain this important role.

The NASA STI Program Office is operated by Langley Research Center, the Lead Center for NASA's scientific and technical information. The NASA STI Program Office provides access to the NASA STI Database, the largest collection of aeronautical and space science STI in the world. The Program Office is also NASA's institutional mechanism for disseminating the results of its research and development activities. These results are published by NASA in the NASA STI Report Series, which includes the following report types:

- $\quad$ TECHNICAL PUBLICATION. Reports of completed research or a major significant phase of research that present the results of NASA programs and include extensive data or theoretical analysis. Includes compilations of significant scientific and technical data and information deemed to be of continuing reference value. NASA's counterpart of peerreviewed formal professional papers but has less stringent limitations on manuscript length and extent of graphic presentations.

- TECHNICAL MEMORANDUM. Scientific and technical findings that are preliminary or of specialized interest, e.g., quick release reports, working papers, and bibliographies that contain minimal annotation. Does not contain extensive analysis.

- CONTRACTOR REPORT. Scientific and technical findings by NASA-sponsored contractors and grantees.
- CONFERENCE PUBLICATION. Collected papers from scientific and technical conferences, symposia, seminars, or other meetings sponsored or cosponsored by NASA.

- SPECIAL PUBLICATION. Scientific, technical, or historical information from NASA programs, projects, and missions, often concerned with subjects having substantial public interest.

- TECHNICAL TRANSLATION. Englishlanguage translations of foreign scientific and technical material pertinent to NASA's mission.

Specialized services that complement the STI Program Office's diverse offerings include creating custom thesauri, building customized databases, organizing and publishing research results ... even providing videos.

For more information about the NASA STI Program Office, see the following:

- Access the NASA STI Program Home Page at http://www.sti.nasa.gov

- E-mail your question via the Internet to help@sti.nasa.gov

- Fax your question to the NASA Access Help Desk at 301-621-0134

- Telephone the NASA Access Help Desk at 301-621-0390

- Write to:

NASA Access Help Desk

NASA Center for AeroSpace Information 7121 Standard Drive

Hanover, MD 21076 
NASA/CR-2005-213817

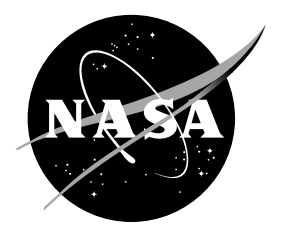

\section{Identification of Noise Sources in High Speed Jets via Correlation Measurements-A Review}

Jayanta Panda

Ohio Aerospace Institute, Brook Park, Ohio

Prepared for the

11th Aeroacoustics Conference

cosponsored by the American Institute of Aeronautics andAstronautics

and the Confederaton of European Aerospace Societies

Monterey, California, May 23-25, 2005

Prepared under Cooperative Agreement NCC3-1019

National Aeronautics and

Space Administration

Glenn Research Center 


\section{Acknowledgments}

This work was supported by NASA's Ultra Efficient Engine Technology and Quiet Aircraft Technology programs. Contribution of Richard G. Seasholtz (retired), NASA Glenn, in the Rayleigh scattering instrumentation development was central to many of the successes. Help from Kristie Elam, Jacobs Sverdrup, and Amy Mielke, NASA Glenn, is acknowledged.

This report is a formal draft or working

paper, intended to solicit comments and

ideas from a technical peer group.

This report contains preliminary

findings, subject to revision as analysis proceeds.

Available from

NASA Center for Aerospace Information 7121 Standard Drive

Hanover, MD 21076
National Technical Information Service 5285 Port Royal Road Springfield, VA 22100 


\title{
Identification of Noise Sources in High Speed Jets via Correlation Measurements-A Review
}

\author{
Jayanta Panda \\ Ohio Aerospace Institute \\ Brook Park, Ohio 44142
}

\begin{abstract}
Significant advancement has been made in the last few years to identify noise sources in high speed jets via direct correlation measurements. In this technique turbulent fluctuations in the flow are correlated with far field acoustics signatures. In the 1970's there was a surge of work using mostly intrusive probes, and a few using Laser Doppler Velocimetry, to measure turbulent fluctuations. The later experiments established "shear noise" as the primary source for the shallow angle noise. Various interpretations and criticisms from this time are described in the review. Recent progress in the molecular Rayleigh scattering based technique has provided a completely non-intrusive means of measuring density and velocity fluctuations. This has brought a renewed interest on correlation measurements. We have performed five different sets of experiments in single stream jets of different Mach number, temperature ratio and nozzle configurations. The present paper tries to summarize the correlation data from these works.
\end{abstract}

\section{Introduction}

The task of jet noise source identification is important for various industrial applications, most notably for aircraft noise abatement programs. In spite of the last half century of work, there is no unanimous agreement on the physics of jet noise emission. This has hampered development of physics-based prediction techniques. It is fair to say that a lot of discrepancies remain in predicting the low frequency, most energetic part of noise from a simple round nozzle using the existing models. The prediction techniques use simplified models of fairly complex two-point spacetime statistics measured in real jets. The sources need to be multiplied by suitable Green's function and integrated over the entire plume to recover the far field sound pressure fluctuations. ${ }^{1}$ Experimental measurements of two-point statistics do not directly provide noise sources. Noise generation is fundamentally a coupling problem where energy from a small part of the turbulent fluctuations, that achieve sonic phase speed in the ambient, is ultimately radiated as sound. Separation of this tiny part from the large turbulent motion is indeed a difficult problem. It has become a common practice to use microphone arrays to determine sound sources solely from the far field measurements. Its advantage lies in its simplicity and the avoidance of measuring complex turbulent flow; the source being modeled simply as a distribution of monopoles. However, the noise sources are expected to have certain spatial coherence and preferred directivity which are yet to be correctly established. Besides, it is difficult to incorporate these parameters in the phased array processing. It can be argued that an independent means of source identification can neither be achieved by only turbulence measurement, nor by sole observations from the far field, but through a simultaneous measurement of the cause (turbulent fluctuations) and the effect (far field noise); this is the approach of the present study.

By definition, correlation measurements require a priori knowledge of the far-field pressure fluctuations. Hence, it can not be used as inputs to the noise prediction codes. It is expected that there are three different usages of the correlation data. First, the validation of postulated source mechanisms in various jet noise theories. The experimental data may or may not follow the trends expected from certain theories. The second usage is simply as a diagnostic tool to identify changes in the noise sources caused by changing plume properties or by nozzle contouring. Third, the validation and debugging of computational aeroacoustics codes that strive to predict far field noise directly.

Although first introduced more than 30 years ago by Siddon, ${ }^{2}$ significant advancements in correlation measurements were made in the last five years with the advent of the molecular Rayleigh scattering technique. In the following results and observations from the earlier work are first presented. This is followed by an elaborate summary of results obtained over the last five years. 


\section{Prior Work}

The direct correlation between the cause and effect was originally proposed by Siddon $^{2}$ (also see Rackl ${ }^{3}$ ) to locate sound sources. A surge of enthusiasm appeared during the 1970's when many experimentalists took up the method. The primary objective of these experiments was to validate various theories such as the self and shear noise theory of Ribner, ${ }^{4}$ fluid dilation model of Meecham \& Ford, ${ }^{5}$ and coherent pressure fluctuations model of Michalke \& Fuchs. ${ }^{6}$ The first one obtained most of the attention, where far field sound pressure fluctuations were correlated to the turbulent velocity fluctuations inside the jet. ${ }^{7-10}$ The last two required correlations with the pressure fluctuations ${ }^{11-12}$ inside the jet. The noise generation theories are still discussed, but significant doubts have been expressed in many of the experimental results. Usually a microphone with a nose cone is inserted into the flow to measure pressure fluctuations. Very high correlation values $\sim 0.4$ were measured between the flow and far field pressure fluctuations; ${ }^{12}$ however, it is difficult to separate out the true correlation values from that caused by probeinterference. The same is true for velocity measurements by hot-wire probes. ${ }^{7,8}$ Richarz ${ }^{10}$ writes, "Although the noise radiation from a hot-wire probe is completely masked by jet noise, it may contribute to the measured jet flow-jet noise correlation nevertheless. A little thought will show that the unsteady forces acting upon the probe are proportional to the velocities measured by it. Therefore, the probe noise and velocity signal are well correlated." With this realization a small number of the early researchers, most notably Schaffar ${ }^{9}$ and Richarz, ${ }^{10}$ resorted to non-invasive Laser Doppler Velocimetry (LDV) for flow-fluctuation measurements. The rest of this section will discuss some of their results.

The theoretical basis for the correlation measurements are from Proudman's version of the Lighthill's acoustic analogy equation. The far field pressure fluctuations p'at the observer position $\mathbf{X}_{\mathbf{f}}$ is due to the turbulent momentum flux $\rho u_{r} u_{r}$ along the direction of the observer ( $\rho$ is the gas density, and $u_{r}$ is the velocity vector along the observer direction, figure 1 ):

$$
\mathrm{p}^{\prime}\left(\mathbf{X}_{\mathbf{f}} ; \mathrm{t}\right)=\frac{1}{4 \pi \mathrm{a}_{0}^{2} \mathbf{r}} \int_{\mathbf{V}} \frac{\partial^{2}}{\partial \mathrm{t}^{\prime 2}}\left[\rho \mathrm{u}_{\mathbf{r}} \mathrm{u}_{\mathbf{r}}\left(\mathbf{X}_{\mathbf{s}} ; \mathrm{t}^{\prime}\right)\right] \mathrm{d}^{3} \mathbf{X}_{\mathbf{s}}
$$

Where $\mathbf{X}_{\mathrm{s}}$ is location inside the jet, $\mathbf{r}=\mathbf{X}_{\mathbf{f}}-\mathbf{X}_{\mathbf{s}}$ is radial distance, $\mathrm{a}_{0}$ is the ambient sound speed, and the integration is carried out at a retarded time $\mathrm{t}^{\prime}=\mathrm{t}-\tau_{0}, \tau_{0}=\left|\mathbf{X}_{\mathbf{f}}-\mathbf{X}_{\mathbf{s}}\right| / \mathrm{a}_{0}$. The above description neglects viscous effects and the contribution from the "second source," i.e., temperature fluctuations. To obtain acoustic intensity an auto-correlation function needs to be worked out. In the "causality" formulation this is accomplished by multiplying the source integral with the far field sound pressure fluctuations:

$$
\begin{aligned}
& \left\langle\mathrm{p}^{\prime 2}\right\rangle\left(\mathbf{X}_{\mathbf{f}} ; \tau\right)= \\
& \left\langle\left[\frac{1}{4 \pi \mathrm{a}_{0}^{2} \mathbf{r}} \int_{\mathbf{v}} \frac{\partial^{2}}{\partial \mathrm{t}^{\prime 2}}\left[\rho \mathrm{u}_{\mathbf{r}} \mathrm{u}_{\mathbf{r}}\left(\mathbf{X}_{\mathbf{s}} ; \mathrm{t}^{\prime}+\tau\right)\right] \mathrm{d}^{3} \mathbf{X}_{\mathrm{s}}\right]\left[\mathrm{p}^{\prime}\left(\mathbf{X}_{\mathbf{f}} ; \mathrm{t}\right)\right]\right\rangle \\
& =\frac{1}{4 \pi \mathbf{r} \mathrm{a}_{0}^{2}} \int_{\mathbf{V}} \frac{\partial^{2}}{\partial \tau^{2}}\left[\mathrm{R}_{\rho \mathrm{u}_{\mathbf{r}} \mathrm{u}_{\mathbf{r}} ; \mathrm{p}^{\prime}}\left(\mathbf{X}_{\mathbf{s}}, \mathbf{X}_{\mathbf{f}} ; \tau\right)\right] \mathrm{d}^{3} \mathbf{X}_{\mathrm{s}} \\
& \mathrm{R}_{\rho \mathrm{uu}_{\mathbf{r}} \mathrm{u}_{\mathbf{r}} ; \mathrm{p}^{\prime}}\left(\mathbf{X}_{\mathbf{s}}, \mathbf{X}_{\mathbf{f}} ; \tau\right)=\left\langle\rho \mathrm{u}_{\mathbf{r}} \mathrm{u}_{\mathbf{r}}\left(\mathbf{X}_{\mathrm{s}} ; \mathrm{t}+\tau-\tau_{0}\right) \mathrm{p}^{\prime}\left(\mathbf{X}_{\mathbf{f}} ; \mathrm{t}\right)\right\rangle
\end{aligned}
$$

The $<>$ bracketed expressions imply time averages. Such time averages are also expressed with an additional semi-colon, e.g. $<\rho u_{r} u_{r} ; p^{\prime}>$, in the text. The above equation says that the auto-correlation of the sound pressure fluctuations can be obtained from the cross correlation of the fluctuating source terms and the radiated noise.

In the past, density fluctuations have been neglected from the source term; although it introduces error, especially for heated and higher Mach number jets. (In the primary plume of a typical turbofan engine $\left.\rho^{\prime} / \bar{\rho} \sim 0.4\right)$. Ribner also decomposed instantaneous velocity into time-averaged and fluctuating parts: $\mathrm{u}_{\mathrm{r}}=\overline{\mathrm{u}_{\mathrm{r}}}+\mathrm{u}_{\mathrm{r}}^{\prime}$. This splits the flow-sound crosscorrelation into two parts:

$$
\begin{aligned}
& \mathrm{R}_{\rho \mathrm{u}_{\mathbf{r}} \mathrm{u}_{\mathbf{r}} ; \mathrm{p}^{\prime}}\left(\mathbf{X}_{\mathbf{s}}, \mathbf{X}_{\mathbf{f}} ; \tau\right)=2 \bar{\rho} \overline{\mathrm{u}_{\mathbf{r}}}\left\langle\mathrm{u}_{\mathbf{r}}^{\prime}\left(\mathbf{X}_{\mathbf{s}} ; \mathrm{t}+\tau-\tau_{0}\right) \mathrm{p}^{\prime}\left(\mathbf{X}_{\mathbf{f}} ; \mathrm{t}\right)\right\rangle \\
& +\bar{\rho}\left\langle u_{\mathbf{r}}^{\prime} u_{\mathbf{r}}^{\prime}\left(\mathbf{X}_{\mathbf{s}} ; t+\tau-\tau_{0}\right) p^{\prime}\left(\mathbf{X}_{\mathbf{f}} ; t\right)\right\rangle
\end{aligned}
$$

The first term on the left is the 'shear noise' source and the second is the 'self noise' source. The relative importance of these terms in noise radiation at different polar angles is still under debate. One important observation of Schaffar ${ }^{9}$ and Seiner and Reethof ${ }^{8}$ is that in the shallow angle to the jet axis the 'shear noise' exceeds 'self noise' by at least $17 \mathrm{~dB}$.

In both LDV and hot-wire based measurements only the axial component of velocity $u$ was measured; the component along the observer direction was 
determined by multiplying with suitable direction cosines. The low speed jet, $\mathrm{Mj}=0.3$, used by Richarz ${ }^{10}$ and Seiner \& Reethof ${ }^{8}$ produced extremely small correlation coefficients. The latter had to use narrowband processing to get any signal at all. Typical values of the normalized correlation $\left\langle\mathrm{u}^{\prime} ; \mathrm{p}^{\prime}\right\rangle / \mathrm{u}_{\mathrm{rms}} \mathrm{p}_{\mathrm{rms}}$ was 0.005 (subscript rms stands for root-mean-square) in Richarz's experiment. Schaffar, on the other hand, used a higher speed $\mathrm{Mj}=0.98$ jet, where maximum correlation value increased to 0.05 . This dependency of the correlation coefficients on jet velocity was confirmed later from the Rayleigh scattering based measurements. ${ }^{13,14}$ The ultimate success of the prior causality work appeared when Schaffar calculated the volume integral in equation (2) from a plume survey. For correlations measured from a fixed microphone, positioned at shallow $160^{\circ}$ and $150^{\circ}$ angles, time derivative and integration following equation (2) reproduced the microphone auto-spectrum (fig. 2). Although a large number of approximations had to be made, yet the result showed that axial velocity fluctuations $\mathrm{u}^{\prime}$ (not $\mathrm{u}^{\prime} \mathrm{u}^{\prime}$ the self-noise source) are responsible for noise at shallow angles. Schaffar failed to measure any correlation with either $\mathrm{u}^{\prime}$ or $\mathrm{u}^{\prime 2}$ terms for microphone polar angle $\theta_{\mathrm{p}}>135^{\circ}$. Such a steep drop in correlation coefficients is also confirmed in recent measurements.

Publications on correlation study for jet noise became sparse at the beginning of 1980s. Perhaps, the realization of the intrusiveness of the easily available probes, criticisms on the interpretation of the data, and receding interest on the jet noise problem contributed to the decline.

\section{Recent Work}

The overarching interest of the prior work was to validate different noise generation theories via correlation measurements. Efforts to validate the causality principle of equation (2) using recent data produced confusing results. At certain microphone polar angles no correlation can be measured; therefore the causality relationship cannot be applied. Yet at certain other polar angles correlations were so high that a unit volume at the end of the potential core is found to produce more noise than the entire jet. ${ }^{13}$ Therefore, the primary focus of the recent work was to find the nature of the correlation coefficients from different plume conditions and nozzle configurations without definite association with any theory.
The correlation technique has been revisited in the last few years with the aid of a new molecular Rayleigh scattering based instrumentation that is capable of measuring unsteady density and velocity fluctuations in heated, high speed flows. ${ }^{14,15}$ Fluctuations occurring over a frequency range of 0 to $50 \mathrm{kHz}$ have been measured. The technique is based on laser light scattering from the gas molecules present in air. Since neither any seed particles nor any intrusive probes are used, the technique is truly non-invasive. Implementation of the technique requires special attention to the cleanliness of the air stream, isolation of the sensitive optical components from jet noise, usage of Fabry-Perot interferometer, low-level light measuring electronics and minimization of the impact of electronic shot noise during signal processing.

Molecular Rayleigh scattering technique.-To limit the length of this paper detail description of the instrumentation is avoided; that can be found in references 13 to 17. An advantage of the Rayleigh scattering technique is that in addition to the fluctuations in any velocity components, fluctuations in scalar variable, such as density (and in theory temperature), are measurable. So far, advancement is made in simultaneous measurement of density and one component of velocity. The central element is a narrow, continuous wave laser beam which is passed through the jet plume that is cleansed of dust particles. Scattered light from a small length of the beam was collected using a set of optics and then analyzed to find the flow properties. The probe volume diameter was about $0.15 \mathrm{~mm}$, and length varied from 0.5 to $1 \mathrm{~mm}$ between setups. For a fixed mixture of gases, such as air, the power of the scattered light is directly dependent on local density. ${ }^{14}$ To measure the time variation of density the variation of the scattered light intensity needed to be monitored. This was accomplished by using a photo-multiplier tube and photo-electron counting electronics. To measure velocity, the Doppler shift of the scattered light from the incident light needed to be measured. An optical spectrum analysis of the scattered light was performed by passing the scattered light through a Fabry-Perot interferometer. ${ }^{15}$ The Fabry-Perot was operated in an imaging mode and the fringe formed at the image plane was monitored. Only a fraction of the freespectral range was used, and all frequency shifts were measured from a single fringe. At first, the interferometer was placed into a control loop that stabilized the position of the reference fringe created by the unshifted incident light. When Doppler shifted 
light was passed through the interferometer the fringe was formed at a different radius. (It's width is also increased due to thermal broadening). To measure the time variation of velocity, the time variation of the shifted fringe needed to be monitored. This was achieved by a pair of concentric mirrors that split the image formed by the interferometer into two parts. The light intensities from the two parts of the fringe were measured by a pair of PMT. An in-situ calibration process was employed where the ratio of the photoelectron counts from the two PMT were measured for different flow velocities. In unknown flows, photoelectron counting was performed in contiguous time bins, which upon multiplication by the calibration constants provided a time history of velocity variations. The scattering geometry was setup to measure either the axial component of velocity $u$ or the radial component $\mathrm{v}$.

All data presented in this paper are from two different single-stream jet facilities at the NASA Glenn Research Center. Table I summarizes the operating conditions and nozzle configurations. Figure 3(a) shows a photograph of an unheated jet facility where one convergent nozzle, two C-D nozzles of design Mach number $\mathrm{Mj}=1.4 \& 1.8$, one 16-lobed rectangular nozzle and one 4-tabbed circular nozzle were tested. ${ }^{13,14,16}$ Table I describes jet velocity in terms of the fluid dynamic Mach number $\mathrm{M}_{\mathrm{j}}$ as well as the acoustic Mach number $M_{a}$. Since noise radiation is a coupling process where flow fluctuations acquire acoustic speed in the ambient, acoustic Mach number is believed to be of more relevance.

In addition to single microphones, a microphone phased array was also employed $;^{18}$ Figure 3(a) shows the setup with a 32 channel array of electret microphones mounted on a semi-cylindrical "bucket" located just below the laser probe volume. The array was concentric with the jet cross-section. It was also traversed with the laser probe volume which was located at the center of the array. The semi-circular array had a radius of 9.25 " and the microphones were arranged in two concentric ellipses. Figure 3(b) shows the Rayleigh setup around the heated jet facility. In both facilities the primary air stream was filtered to remove dust particles. In addition a low speed $(\sim 15 \mathrm{~m} / \mathrm{s})$, clean, co-flowing stream was created around the primary jet to block entraining of the dustladen ambient air. A hydrogen combustor was used in the heated facility to avoid soot particles. The bulk of the correlation data are from single microphones mounted on a 50D (D: nozzle exit diameter) arc for the unheated jet and 100D for the heated jet facility. The laser probe volume was traversed on an x-r plane (x: axial, r: radial directions) containing the jet centerline.

Comparison of correlations from different flow variables. - The unheated $\mathrm{M}_{\mathrm{a}}=0.91,1.18$ and 1.4 jets were investigated using two different Rayleigh setup which measured either $\rho$ and $u$, or $\rho$ and $v$ simultaneously ( $\mathrm{u}$ is the axial and $\mathrm{v}$ is the radial component of velocity). Figure 4 presents normalized $<\rho ; p^{\prime}>,<\rho u u ; p^{\prime}>$ and $<\rho v v ; p^{\prime}>$ cross-correlations from $150^{\circ}$ and $90^{\circ}$ microphone polar angles. The puu product was created by multiplying density $\rho(\mathrm{t})$ and velocity $\mathrm{u}(\mathrm{t})$ time-traces. The cross-correlation values were calculated via Fourier transform, that is, the cross-spectrum $\mathrm{P}_{\rho \mathrm{pu} ; \mathrm{p} /}$ and $\mathrm{P}_{\rho ; \mathrm{p} /}$ were calculated first, and then inverse transforms were taken to return to the time domain. A significant problem with the Rayleigh time series data arose from the electronic shot noise which added a large random white noise to the velocity and density signals. The cross-correlation process minimized contamination from shot-noise. However, the cross-correlation data needed to be normalized by standard deviations of $\rho u u$ and $\rho$ fluctuations which were also contaminated by the shot noise. To reduce this contribution, the standard deviations were calculated from individual spectra from which the shot noise floor was subtracted. The latter was estimated from the highest frequency bin where energy from the turbulent fluctuations was deemed to be minimal. It is estimated that the noise removal process created \pm 10 percent error in the correlation data.

The cross-correlation data of figure 4 show sharp rise at a time delay which slightly exceeds the time needed for sound waves to travel from the laser probe location to that of the microphone with ambient speed, $\tau_{0}=\left(\mathbf{X}_{\mathbf{f}}-\mathbf{X}_{\mathbf{s}}\right) / a_{0}$. The laser probe was located at the centerline and farther downstream from the end of the potential core: a region found to provide the largest correlation. There are multiple interesting observations that can be made from figure 4. First, air density fluctuations show as good a correlation as puu; even the time variations of the correlation data are similar. The same was found to be the case for the correlation with the axial velocity fluctuations $\left\langle\mathrm{u} ; \mathrm{p}^{\prime}\right\rangle$. Therefore, it can be said that the noise sources can be expressed in many different variables. There are, however; other variables which show far poorer correlation. This is the second observation. Unlike $\rho u u, \rho v v$ show significantly lower correlation with the far field noise. That the 
$<\rho v v$; $\mathrm{p}^{\prime}>$ correlation with $90^{\circ}$ microphone is immeasurably small is of particular interest. The causality relation of equation (2) dictates that $\left\langle\rho v v ; p^{\prime}\right\rangle$ correlation as the source for the $90^{\circ}$ noise. Therefore it had been expected that $\left\langle\rho v v ; p^{\prime}>\right.$ correlation from $90^{\circ}$ microphone would be significant, which was found to be incorrect. Similarly causality relation shows that $\rho v v$ fluctuations has little to do with $150^{\circ}$ noise radiation, yet microphone signal from this angle show significant $\left\langle\rho v v ; p^{\prime}\right\rangle$ correlation above the noise floor. Third, sound pressure fluctuations at $90^{\circ}$ to the jet axis correlate poorly with any flow variables. An exception was found in $<\rho$; $p^{\prime}>$ correlation in highly heated jets which will be discussed latter. Fourth, the time duration $\Delta \tau$ over which correlation changes from zero to negative to positive and back to zero is significantly long. For the particular $\mathrm{M}_{\mathrm{a}}=0.95$ jet, $\Delta \tau$ is estimated as $1.2 \mathrm{msec}$. This provides a measure of coherence time of the dynamic process responsible for sound radiation. Invoking Taylor's hypothesis, the corresponding coherence length scale is $l_{\text {coher }}=\Delta \tau \mathrm{U}_{\mathrm{c}}$, where $\mathrm{U}_{\mathrm{c}}$ is the convective speed. Assuming $\mathrm{U}_{\mathrm{c}}=0.7 \mathrm{U}_{\mathrm{j}}$ the coherence length $1_{\text {coher }} \approx 10 \mathrm{D}$. In other words, the longest source contributing towards correlation is, on an average, 10 jet diameters long. Therefore, the noise source responsible for sound radiation, at the shallow $150^{\circ}$ angle, is indeed "non-compact."

Since many of the earlier studies revolved around self and shear noise sources, attempts were made in reference 13 to revisit this division, albeit in a more general way. Unlike the earlier efforts density fluctuations are now measurable; hence there appear additional shear noise term from $\rho^{\prime}$ fluctuation, and self noise terms from $\rho^{\prime} u^{\prime}$ and $\rho^{\prime} u^{\prime} u^{\prime}$ fluctuations:

$$
\begin{aligned}
& \rho=\bar{\rho}+\rho^{\prime}, \quad u=\bar{u}+u^{\prime} \\
& \left\langle\rho u u ; p^{\prime}\right\rangle=\left\langle 2 \bar{\rho} \bar{u} u^{\prime} ; p^{\prime}\right\rangle+\left\langle\rho^{\prime} \bar{u} \bar{u} ; p^{\prime}\right\rangle+ \\
& \left\langle 2 \bar{u} \rho^{\prime} u^{\prime} ; p^{\prime}\right\rangle+\left\langle\bar{\rho} u^{\prime} u^{\prime} ; p^{\prime}\right\rangle+\left\langle\rho^{\prime} u^{\prime} u^{\prime} ; p^{\prime}\right\rangle
\end{aligned}
$$

The five fluctuating terms in puu decomposition were constructed from the measured $\rho(t), u(t)$ time traces and individually correlated with the sound pressure fluctuations. Table II shows relative importance of various terms calculated by uniform normalization. This table confirms that the terms containing first order fluctuation, attributed as shear noise source, provides far higher correlation than the second and third order fluctuations, the self noise sources.

Acoustic Mach number $M_{a}$ and polar angle $\theta_{p}$ dependence $^{*}$. - The largest value of either $\left\langle\rho u u ; p^{\prime}>\right.$ or $\left\langle\rho ; \mathrm{p}^{\prime}>\right.$ correlation is found to be a strong function of the acoustic Mach number. Figure 5 presents plots of the maximum $<\rho ; p^{\prime}>$ correlation measured with the sound pressure fluctuations from microphones kept at different polar angles. Similar dependency in the $<\rho u$; $\mathrm{p}^{\prime}>$ correlations is presented in reference 13 . The normalized correlation coefficients can be interpreted as the efficiency of turbulent fluctuations present at the laser probe volume to radiate to the microphone location. Clearly, such radiation efficiency improves with the Acoustic Mach number. The most significant improvement is seen for fluctuations along the lip line. They are mostly non-radiative in the subsonic $\mathrm{M}_{\mathrm{a}}=0.6$, yet become efficient radiators in the supersonic $\mathrm{M}_{\mathrm{a}}=1.48$ case. Polar-angle-wise, sound pressure fluctuations from the shallowest angle of $150^{\circ}$ show the highest correlation. Correlation values from the $140^{\circ}$ and $130^{\circ}$ microphones are also significant. There occur sharp drops around $120^{\circ}$ and especially for the lower $M_{a}$ jets. For the higher $M_{a}$ jets some correlations are measured even for the $90^{\circ}$ microphone when the laser probe is placed around the end of the potential core. It is believed that the present correlation study, for the most part, is identifying turbulent fluctuations that radiate close to the jet axis.

Effect of heating.-To explore the effect of heating on noise sources, experiments were conducted in a 2" diameter heated jet facility mentioned earlier. (The unheated jet data in figure 6(e) is from the 1" facility). To isolate the effect of heating the plume velocity (and therefore the acoustic Mach number $\mathrm{M}_{\mathrm{a}}$ ) was kept constant, while the jet static temperature was increased by hydrogen burning combustor chamber. Figure 6 presents data from a large range of temperature ratios and demonstrates a direct relationship between the plume temperature and correlation coefficients: an increase in one is reflected similarly in the other. This increase, once again, is most reflected in the peripheral shear layer which hardly radiates in the unheated subsonic jet, yet becomes increasingly efficient as $T_{r}$ is increased. This

\footnotetext{
‡ In references 13, 14, and 16 and prior work in the 1970 s microphone polar angles were measured from the jet flow direction, while for the present document polar angles are presented from the flight direction: $150^{\circ}$ in the present paper is equivalent to $30^{\circ}$ in the earlier.
} 
increase in radiation efficiency may be due to the second source associated with temperature fluctuations in various acoustic analogy equations.

In order to demonstrate the effect of heating, reference 17 presented the coherence spectra of the correlation values. Unlike the time domain correlation values presented in figure 6 , coherence spectra are heavily affected by electronic shot noise. This was particularly true for the $T_{r}=1.0$ jet where the plume and the ambient had nearly the same time averaged density. These led to very small level of fluctuating density and ultimately nearly zero coherence. Some of the conclusion drawn in that paper based on the coherence spectra may not be correct.

Frequency dependence and distributions of noise sources.-So far data from time-domain correlation study were discussed. Such data do not show the frequency dependence of correlation. Towards this goal, coherence spectrum $\Gamma_{\rho^{\prime} \mathrm{p}^{\prime}}^{2}\left(\mathrm{f}_{1}\right)$ was calculated from the time series of the photoelectron counts $\mathrm{N}$ (which multiplied by calibration constants provide air density) and microphone pressure fluctuations:

$\Gamma_{\rho^{\prime} \mathrm{p}^{\prime}}^{2}\left(\mathrm{f}_{1}\right)=\frac{\left|\mathrm{P}_{\mathrm{N}^{\prime} \mathrm{p}^{\prime}}\left(\mathrm{f}_{1}\right)\right|^{2}}{\mathrm{P}_{\mathrm{N}^{\prime} \mathrm{N}^{\prime}}\left(\mathrm{f}_{1}\right) \mathrm{P}_{\mathrm{p}^{\prime} \mathrm{p}^{\prime}}\left(\mathrm{f}_{1}\right)}$

where, $\mathrm{P}_{\mathrm{N}^{\prime} \mathrm{p}^{\prime}}\left(\mathrm{f}_{1}\right)=\frac{2}{\mathrm{n}^{2}}\left(\mathrm{~F}_{\mathrm{N}^{\prime}}\left(\mathrm{f}_{1}\right) . \mathrm{F}_{\mathrm{p}^{\prime}}^{*}\left(\mathrm{f}_{1}\right)\right)$

Here, $\mathrm{F}_{\mathrm{N}^{\prime}}$ represents Fourier transform of timeseries of photo-electron counts, $\mathrm{F}_{\mathrm{p}}^{*}$ is the complex conjugate of the Fourier transform of the microphone signal, $\mathrm{P}_{\mathrm{N}^{\prime} \mathrm{N}^{\prime}}$ and $\mathrm{P}_{\mathrm{p}^{\prime} \mathrm{p}^{\prime}}$ are corresponding power spectra, and $\mathrm{n}$ is the total number of samples used for the calculation. The center frequencies $f_{1}$ were then converted into Strouhal number $\left(S t=f_{l} D / U_{j}\right.$, D: jet diameter, $U_{j}=$ jet exit velocity). One important disadvantage of the coherence spectra is that the effect of shot-noise can not be entirely removed. The crossspectrum mostly rejects this noise, but the power spectrum of photo-electron count contains contribution from both the desired density fluctuations and the undesirable shot noise: $\sum_{\mathrm{f}_{\mathrm{l}}} \mathrm{P}_{\mathrm{N}^{\prime} \mathrm{N}^{\prime}}=\frac{\sigma_{\rho}^{2}}{\text { calibration cons tan } \mathrm{t}}+\sigma_{\text {shot noise }}^{2}$

Where, $\sigma_{\rho}^{2}$ and $\sigma_{\text {shot noise }}^{2}$ represents mean square of respectively, density and shot noise fluctuations. In the unheated low speed jets the later can be much higher than the former, resulting in a large bias towards the lower value in coherence spectrum. The situation worsens for a temperature balanced jet, discussed earlier, where coherence spectrum falls mostly in the noise floor. Nevertheless, the coherence spectrum $\Gamma_{\rho}^{2} \rho^{\prime},(S t)$ provides a measure of linear dependency between turbulent density fluctuations and the far field sound pressure fluctuations. In the absence of shot noise, a coherence value of unity implies a perfectly linear cause and effect relation while a value of zero implies no correlation. Convergence errors and electronic shot noise never allowed attainment of the zero value even in quiescent flows; instead a noise floor around $\Gamma_{\rho^{\prime} p^{\prime}}^{2} \sim$ 0.002 was reached. When the coherence level is above the noise floor, it can be said that some part of density fluctuations from the laser probe location is creating sound pressure fluctuations at the microphone location; in other words, the probe location is a sound source.

The spatial distribution of coherence values at different Strouhal frequencies for two different Mach number jets is shown in figure 7. For this figure a large number of correlation data were measured by moving the laser probe from point to point in the flow, while keeping the microphone location fixed. Later on, coherence values at a desired Strouhal frequency were isolated for all measurement stations and plotted using indicated color scale. Note that the color scale is such that the minimum value (green for $\Gamma=0.005$ ) is above the noise floor $(\Gamma=0.002)$. Therefore regions of no or very low correlation do not show any color. Since no correlation was measured in Mach 0.95 jet for $\mathrm{St} \geq 0.4$, coherence distributions at $\mathrm{St}=.5,1$ and 1.5 are not plotted. A clear distinction in measurable sound sources in subsonic and supersonic jets is visible in this figure. Density fluctuations causing sound generation up to $\mathrm{St}=1.5$ could be determined only in the supersonic case; the higher the frequency the closer the source to the nozzle exit. Additionally, the peripheral shear layer around the potential core is found to produce no correlation in the subsonic jet, while significant correlation at high frequency is measured in the Mach wave emitting supersonic jet. The lower frequency source in both jets is the strongest along centerline, after the end of potential 
core. Such sources weaken rapidly in the radial direction and very slowly in the downstream direction.

Effect of nozzle configuration.-A utility of the correlation method is that it can be used to identify changes in the source distribution made by nozzle contouring or other noise abatement schemes. A comparison of coherence spectra from different nozzle configurations demonstrate this utility (fig. 8). A baseline axisymmetric, a 16 lobe rectangular, and a 4-tab axisymmetric nozzles were used to produce unheated $\mathrm{Mj}=0.95$ jets. ${ }^{16}$ All three nozzles had equivalent diameter $D_{\text {eqv }}$ of 1". The far field noise spectra presented in part (d) of this figure shows that within the Strouhal frequency range of $0 \leq \mathrm{St} \leq 0.6$ the axisymmetric configuration is the loudest and the lobed one is the quietest. The scenario reverses at the higher frequency end. The correlation data in the low frequency side reflects the same trend as seen in the noise spectra. The air density fluctuations present in the axisymmetric configuration is the most effective in sound radiation while the lobed nozzle is the least; the tabbed nozzle falls in between. Note that the coherence data from the tab-nozzle and the lobe-nozzle are shown for axial stations closer to the nozzle exit; this is to reflect the faster mixing and shorter potential core length which brings noise sources closer to the exit. Detailed flow data from these jets were presented in reference 16. Since, no correlation can be measured for St $>0.6$ nothing can be said about the high frequency noise sources.

An interesting double hump behavior in the coherence data from some stations $\left(\mathrm{x} / \mathrm{D}_{\text {eqv }}=3,4\right.$ figure $8(\mathrm{c})$ ) in the tabbed jet plume led to further radial surveys shown in figure 9 . The coherence data from all radial stations at $\mathrm{x} / \mathrm{D}=3$ show the same double hump behavior indicating the existence of two distinct noise sources. It is conjectured that the two sources may be due to the splitting of the jet into a bigger core jet and 4 smaller jetlets outlined in the figure $9(\mathrm{~b})$. The lower frequency part may be attributed to the global length scale from the jet diameter and the higher frequency to the interactions of the small jetlets. Notably, Tam \& Zaman ${ }^{19}$ has proposed a similar jetlet model to explain increased high frequency noise from tabbed nozzle.

Microphone phased array.-Currently the most prevalent experimental tool to identify noise source is a microphone phased array. The distribution of the noise sources obtained by the present correlation technique and by phased array ${ }^{20}$ carries some similarity and some dissimilarity. For example, both determine the end of the potential core as the strongest source for the low frequency noise. Phased array can detect higher frequency noise sources in any jet; the correlation method mostly fails to do so except for the high Mach number conditions. For these instances the progressive upstream shift of the noise source with increase in frequency is a similar result from both techniques. The important differences appear in discriminating noise sources radiating to different polar angles, and spatial resolution in source identification. The correlation technique is deemed superior in these regards. Usually phased arrays cover a large polar angle and the inherent monopole directivity assumption forbids discrimination based on the noise directivity. The large spatial extent of the instrument function translates into poor spatial resolutions in the phased array measurements. For example, the different behavior of the turbulent fluctuations along the lip line and the centerline found in the correlation measurements are difficult to reproduce using phased arrays. There are ongoing efforts to improve spatial resolution via deconvoluting the instrument function from the measured distribution ${ }^{18}$ and by employing caged microphone arrays; still resolution obtainable by the point measurement process in the correlation technique is superior. Nevertheless, phased array technique avoids turbulence measurement which explains its omnipresence.

It was conjectured that the lack of correlation in the high frequency range may lie with the usage of a single far field microphone. Since noise sources are distributed over the entire plume, the contribution from the small probe volume was overwhelmed by radiation from large number of distributed sources. A microphone phased array, on the other hand, is capable of extracting sound pressure fluctuations from a localized region of the jet. Therefore, a combined phased-array and Rayleigh scattering experiment was undertaken. ${ }^{18}$ Figure 3(a) shows a photograph of the semi-cylindrical array of 32 microphones mounted on the jet facility. Note that the array was designed to cover a large azimuthal angle and a small polar angle, which made a narrower instrument function in the radial direction and a larger one in the axial direction. In other words, for the same Strouhal frequency the array was able to localize sources more precisely in the radial direction than in the axial direction. Experimental data from the combined phased array and microphone measurements can be found in reference 18. The large number of microphones used in the test allowed examination of the azimuthal variation of the correlation coefficients and the nature of the 
acoustic phase fronts emitted by the jet. Only these parts are described in the following.

Figures 10(a) and (b) allow a closer examination of the correlation data from different microphones located inside the phased array. Note that the microphones used in the part (a): number 0, 23, 29, and 10, lie parallel to the jet axis with 0 being the most downstream and 10 as the most upstream. The separation between these two is $6.2 \mathrm{D}$. The laser probe volume lies at the center of the pattern. Microphone used in figure $10(\mathrm{~b})$ : number $5,20,23,26$, and 15 , lie at fixed axial position $(x / D=8)$ but at different azimuthal angles (microphone 23 is slightly upstream). Figure 10(b) is easier to explain: since the correlation data are all in phase, the sound source associated with the density fluctuations at the probe location is axisymmetric in nature. The different shapes of the correlation profile in the figure 10(a) perhaps indicate axial distortions of the phase front radiated from the probe location.

Figure 10(c) shows correlation with the beam-

formed signal $\mathrm{p}_{\mathrm{bf}}: \frac{\left\langle\rho^{\prime} ; \mathrm{p}_{\mathrm{bf}}^{\prime}\right\rangle}{\rho_{\mathrm{rms}}^{\prime}\left(\mathrm{p}_{\mathrm{bf}}^{\prime}\right)_{\mathrm{rms}}}$. The beam-formed

time series was calculated by applying estimated propagation delay $\tau_{\mathrm{i}}$ from the probe volume to the individual microphones:

$\mathrm{p}_{\mathrm{bf}}\left(t^{\prime}\right)=\frac{1}{32} \sum_{\mathrm{i}=0}^{31} \mathrm{p}_{\mathrm{i}}\left(\mathrm{t}+\tau_{\mathrm{i}}\right)$

The correct estimate of the time delay lies at the heart of the beam-steering process employed in the phased array processing. The non-compactness of the jet noise source, as evident from the long time duration of the correlation data makes it difficult to choose a single time delay. By increasing the time delay one may intend to steer the array to a further location, but that is also equivalent to looking at a different phase of the acoustic front arriving from a nearby point. This exemplifies the central problem of beam forming when the noise source is non-compact. For the effort of improving correlation via beam-forming, it was decided to use the simplest free-space propagation time for time delay estimates. Figure 10(c) shows an improvement of correlations by a factor of two. Data obtained from some other locations, for example the peripheral shear layer close to the nozzle exit, however, did not show much improvement. A frequency analysis, showed the same absence of correlation for $\mathrm{St}>0.6$ found in the single microphone data.

\section{Interpretation of Correlation Data}

The large value of correlation measured from certain locations in the jet and microphone polar angles and its near absence from the other are indicative of interesting noise source behavior. Attempts to associate correlation data with various noise generation theories are bound to generate debates. The following describes some criticisms and plausible explanations.

Criticism of the causality approach's. - The primary criticism of the causality approach is that the existence of correlation is not sufficient proof that the measured turbulent fluctuations are the sources of far field noise. Both may be the result of an unidentified forcing function. It is interesting to read criticism of Professor J.E. Ffowcs Williams and rebuttal from Professor T.E. Siddon in a discussion session, at the end of the 1973 AGARD meeting. ${ }^{21}$ Ffowcs Williams: "...if you were to measure the sound produced by my voice at the lips of Prof. Küchemann and at the ears of somebody beyond him you would find that the correlation between the pressures was perfect. Yet is Prof. Küchemann talking or am I?" In rebuttal Prof. Siddon replied," ...correlations, if normalized by the individual root mean square values of the partner variables, will give an erroneous impression of the source distribution. For example, two microphones both in the far field of, but on a radial line from a complex source will give a maximum correlation coefficient of unity, when normalized in the foregoing manner. In contradistinction the un-normalized causality functions...yield legitimate distribution functions which quickly drop to zero outside the source region.." Perhaps, "quickly drop to zero" should be replaced by: quickly drop to very small value. Nevertheless, the value of Prof. Siddon's rebuttal becomes apparent by examining the un-normalized values of $<\rho u u ; p^{\prime}>$ correlations. The largest fluctuation present in a jet is due to the fluctuating axial momentum flux $\rho u u$, and this term is seen to be well correlated with the shallow angle noise. Radial variation of un-normalized correlation, measured by a moving probe and a fixed microphone, is show in figure 11. This figure shows that the un-normalized $<$ puu; $p^{\prime}>$ drops by a factor of 100 when the laser probe is moved from the jet centerline to the edge of the turbulent plume. There exist $\rho, \mathrm{u}$ and $\mathrm{p}$ fluctuations in the free-field outside the jet boundary. But the absolute values of these fluctuations are so small that the laser 
probe is unable to detect their presence. The difficulty of separating the source fluctuations from that of a passing sound wave is that the fluctuations in the same variables appear in both. Therefore, the physical expectation of the strongest fluctuations as the source and the weaker fluctuations as the effect ultimately differentiates the two.

Turbulence as a sum of random eddies.Correlation coefficients can be interpreted as the radiation efficiency of the fluctuations present at the probe volume. In the past efforts were made to associate the fluctuations with individual turbulent eddies. ${ }^{7,8}$ This stem from a picture of turbulence which is well described by Lee \& Ribner: " A turbulent jet may be regarded as an assemblage of 'eddies' (correlation volumes) which radiate sound independently and incoherently; the pressure contribution from each adds in the mean square at points in the far field." Based on their measured correlation of 0.002 Lee and Ribner estimated that about 2500 eddies of equal strength radiates to the far field. This was used to determine sound emission per unit length of the jet. An examination of the earlier data shows that the measurable correlation was found only in the low Strouhal frequency range 0 to 0.5 . It is now known that, over this frequency range, turbulence as incoherent eddies provides an incorrect description of reality. Therefore, the idea of calculating number of eddies generating sound is no longer persuasive.

Large-scale versus fine-scale noise source.Various aspects of the correlation data are better explained from a structural description of jet turbulence (Tam et al., ${ }^{22}$ Michalke $^{23}$ ). The sound pressure fluctuations measured by a far field microphone are due to a sum of the radiation from all turbulent eddies distributed in the entire jet plume. However, based on the extent of spatial coherence, the eddies can be broadly divided into large structures with coherence length scales of the order of a jet diameter, and fine structures of much smaller spatial coherence. Figure 12 provides a schematic description of the situation. It is believed that the present experiment picks up contribution from the large structures and is unable to determine contribution from fine scale, small eddies. Although the current technique measures correlation from a single point in the plume, the correlation values are extremely high for shallow angles. The radiation from various spatial locations of large structures is expected to be phase related; therefore, a single point correlation reflects contribution from the entire correlated source.
Theoretical calculations of Michalke ${ }^{23}$ show that the higher the spatial correlation of turbulence, the narrower the radiation angle. Additionally, frequency analysis of cross-correlation data demonstrates that the measured correlations are from low Strouhal frequency fluctuations. These are characteristics of large organized structures which radiate primarily in the downstream direction close to the jet axis. The quick drop in correlation with an increase of microphone polar angle, seen in figures 5 and 6 , is reflective of the inefficiency of the large scale structures to radiate at $90^{\circ}$ or upstream angles. According to the model of Tam et al. ${ }^{22}$ fine-scale structures with little spatial coherence are primarily responsible for sound radiation at $90^{\circ}$ and lower polar angles. Such eddies radiate more omni-directionally; the net sound field at a far field point is a sum of the contributions from many such eddies with random phase relationships. Hence, correlation from a single measurement point in the plume is expected to be very small, below the experimental noise floor. This perhaps explains inability of the present point measurement scheme to identify noise sources for the $90^{\circ}$ radiation.

\section{Concluding Comments}

The correlation method to identify noise sources has remained an exclusively experimental effort. Computational aero-acoustics did not exist in the 1970's. It will be of interest to see modern computational efforts to replicate some of the observations made from the experiment. The experimental data can also be used to determine the resolvable frequency range in the large eddy simulation and the usefulness of direct numerical simulation for predicting noise from large Reynolds number jets.

Experimentally the lack of correlation for St $>0.5$ (St $>1$ for $\mathrm{Ma}>1$ jets) has remained a challenge. Further innovative experiments are required for the future progress. The computational approaches can also be used to diagnose the underlying reasons.

\section{Reference}

${ }^{1}$ Goldstein, M.E. 1976 Aeroacoustics, McGraw-Hill International Book Co., New York.

${ }^{2}$ Siddon, T.E. 1973 Noise source diagnostics using causality correlations, AGARD CP 131, Noise Mechanisms 7-1:7-13. 
${ }^{3}$ Rackl, R. 1973 Two causality correlation techniques applied to jet noise, Ph. D. thesis, University of British Columbia.

${ }^{4}$ Ribner, H.S. 1969 Quadrupole correlations governing the pattern of jet noise, J. Fluid Mech., 38, 1-24.

${ }^{5}$ Meecham, W.C. \& Ford, G.W. 1958 Acoustic radiation from isotropic turbulence, J. Acoust. Soc. Am. 30, 318-322.

${ }^{6}$ Michalke, A. \& Fuchs, H.V. 1975 On turbulence and noise of an axisymmetric shear flow, J. Fluid Mech., 70, 179-205.

${ }^{7}$ Lee, H.K., \& Ribner, H.S. 1972 Direct correlation of noise and flow of a jet. J. Acoustic. Soc. Of America. 52, no. 5 (pt. 1) 1280-1290.

${ }^{8}$ Seiner, J.M. \& Reethof, G. 1974 On the distribution of source coherency in subsonic jets. AIAA paper 74-4.

${ }^{9}$ Schaffar, M. 1979 Direct measurements of the correlation between axial in-jet velocity fluctuations and far field noise near the axis of a cold jet. J. Sound \& Vib. 64 (1) 73-83.

${ }^{10}$ Richarz, W.G. 1980 Direct correlation of noise and flow of a jet using Laser Doppler. AIAA J. 18(7), 759765 .

${ }^{11}$ Hurdle, P.M., Meecham, W.C. \& Hodder, K. 1974 Investigation of the aerodynamic noise generation region of a jet engine by means of the simple source fluid dilatation model. J. Acoustical Soc. Of America, 56, 1708-1721.

${ }^{12}$ Armstrong, R.R., Michalke, A. \& Fuchs, H.V. 1977 Coherent structures in jet turbulence and noise. AIAA J. 15 (7), 1011-1017.

${ }^{13}$ Panda, J., Seasholtz, R.G. \& Elam, K.A. "Further Progress in Noise Source Identification in High Speed Jets Via Causality Principle," to appear in Journal of Fluid Mechanics, 2005.
${ }^{14}$ Panda, J. \& Seasholtz, R.G. "Experimental investigation of density fluctuations in high-speed jets and correlation with generated noise," Journal of Fluid Mechanics, vol. 450, pp. 97-130, 2002.

${ }^{15}$ Seasholtz, R.G., Panda, J. \& Elam, K.A. 2002 Rayleigh Scattering Diagnostic for Measurement of Velocity and Density Fluctuation Spectra. $40^{\text {th }}$ AIAA Aerospace Sciences meeting, AIAA paper no 20020827.

${ }^{16}$ Panda, J. and Zaman, K.B. M.Q. "Density fluctuation in asymmetric nozzle plumes and correlation with far field noise." AIAA paper 2001-0378, 2001.

${ }^{17}$ Panda, J., Seasholtz, R.G., Elam, K.A., Mielke, A.F. \& Eck, D.G. "Effect of heating on Turbulent Density Fluctuations and Noise generation from high speed jets," AIAA-2004-3016, June 2004.

${ }^{18}$ Dougherty, R., Panda, J. \& Lee, S. "Non-intrusive jet noise study combining Rayleigh scattering and phased array measurement techniques," AIAA paper 20052843.

${ }^{19}$ Tam, C.K. W. \& Zaman, K.B.M.Q. "Subsonic jet noise from non-axisymmetric and tabbed nozzles," AIAA J., 38 (4), 592-599, April, 2000.

${ }^{20}$ Lee S. \& Bridges, J. 2005 Phased- Array Measurements of Single Flow Hot Jets, AIAA paper 2005-2842.

${ }^{21}$ Noise Mechanisms AGARD CP 131, 1973, Brussels, Belgium

${ }^{22}$ Tam, C.K. W., Golebiowski, M. \& Seiner, J.M. 1996

On the Two Components of Turbulent Mixing Noise from Supersonic Jets. AIAA Paper 96-1716.

${ }^{23}$ Michalke, A. 1983 Some remarks on source coherence affecting jet noise. J. Sound \& Vib. 87 (1), $1-17$. 
Table I**.-Operating condition, nozzle geometry etc.

\begin{tabular}{|c|c|c|c|c|c|}
\hline Reference & $\begin{array}{l}\text { Acoustic } \\
\text { Mach no, } \\
M_{a}=U_{j} / a_{0}\end{array}$ & $\begin{array}{c}\text { Jet Mach no., } \\
\mathrm{M}_{\mathrm{j}}=\mathrm{U}_{\mathrm{j}} / \mathrm{a}_{\mathrm{j}}\end{array}$ & $\begin{array}{c}\text { Static temp ratio, } \\
\mathrm{T}_{\mathrm{r}}\end{array}$ & Nozzle config. & Comments \\
\hline 13,14 & 0.911 & 0.95 & 0.853 & Round & $\begin{array}{l}\text { Also investigated using } \\
\text { mic phased array (ref. 18) }\end{array}$ \\
\hline 13,14 & 1.18 & 1.4 & 0.725 & Round & C-D nozzle \\
\hline 13,14 & 1.4 & 1.8 & 0.614 & Round & C-D nozzle \\
\hline 13,14 & $\begin{array}{l}0.58,0.67 \\
0.77,0.84\end{array}$ & $0.6,0.7,0.8,0.9$ & $\begin{array}{l}0.93,0.91,0.886 \\
0.86\end{array}$ & Round & Limited data \\
\hline 17 & 0.9 & $\begin{array}{l}0.982,0.9,0.754 \\
0.671,0.604\end{array}$ & $\begin{array}{l}0.84,1.0,1.429 \\
1.818,2.273,2.7\end{array}$ & Round & $\begin{array}{l}\text { Cases with fixed } M_{a} \text { but different } \\
\text { TR }\end{array}$ \\
\hline 17 & $0.6,0.9,1.48$ & $0.402,0.604,0.993$ & 2.273 & Round & $\begin{array}{l}\text { Cases with fixed TR but } \\
\text { different } \mathrm{M}_{\mathrm{a}}\end{array}$ \\
\hline 16 & & 0.95 & 0.85 & Round, tabbed & Asymmetric nozzle \\
\hline 16 & & 0.95 & 0.85 & $\begin{array}{l}\text { Rectangular } \\
\text { lobe nozzle }\end{array}$ & Rectangular nozzle \\
\hline
\end{tabular}

**Typical operating condition of a modern turbofan engine: Primary flow: $\mathrm{M}_{\mathrm{a}}=1.5, \mathrm{Tr}=2.27$; Fan flow: $\mathrm{M}_{\mathrm{a}}=0.98, \operatorname{Tr}=1.01$.

Table II.-Peak correlation coefficients between far field sound pressure fluctuations and various Reynolds decomposed terms of puu:

\begin{tabular}{|c|c|c|c|c|c|c|c|}
\hline Mach & $\begin{array}{l}\text { Probe } \\
x / D\end{array}$ & $\begin{array}{l}\text { Probe } \\
\text { r/D }\end{array}$ & $\begin{array}{l}\text { Mic } \\
\text { ang }\end{array}$ & $\left\langle\rho u u ; p^{\prime}\right\rangle$ & $\left\langle 2 \overline{\rho u}^{--} ; \mathrm{p}^{\prime}\right\rangle$ & $\left\langle\rho^{\prime} \bar{u} \bar{u} ; p^{\prime}\right\rangle$ & $\left\langle 2 \overline{\mathrm{u}} \rho^{\prime} \mathrm{u}^{\prime} ; \mathrm{p}^{\prime}\right\rangle$ \\
\hline no. & & & & $(\rho u u)_{\mathrm{rms}} \mathrm{p}_{\mathrm{rms}}^{\prime}$ & $(\rho u u)_{\mathrm{rms}} \mathrm{p}_{\mathrm{rms}}^{\prime}$ & $\overline{(\rho u u})_{\mathrm{rms}} \mathrm{p}_{\mathrm{rms}}^{\prime}$ & $(\rho u u)_{\mathrm{rms}} \mathrm{p}_{\mathrm{rms}}^{\prime}$ \\
\hline 1.8 & 12 & 0 & $150^{\circ}$ & 0.2207 & 0.1635 & 0.0636 & -0.00214 \\
\hline 1.8 & 12 & 0 & $90^{\circ}$ & 0.0056 & 0.0033 & 0.0023 & Noise \\
\hline 1.4 & 10 & 0 & $150^{\circ}$ & 0.1919 & 0.1344 & 0.0624 & -0.0021 \\
\hline 0.95 & 10 & 0 & $150^{\circ}$ & 0.0682 & 0.0592 & 0.01 & -0.0002 \\
\hline
\end{tabular}

\begin{tabular}{|cc|}
\hline$\frac{\left\langle\rho \mathrm{u}^{\prime} \mathrm{u}^{\prime} ; \mathrm{p}^{\prime}\right\rangle}{(\rho \mathrm{puu})_{\mathrm{rms}} \mathrm{p}_{\mathrm{rms}}^{\prime}}$ & $\frac{\left\langle\rho^{\prime} \mathrm{u}^{\prime} \mathrm{u}^{\prime} ; \mathrm{p}^{\prime}\right\rangle}{(\rho \mathrm{\rho u})_{\mathrm{rms}} \mathrm{p}_{\mathrm{rms}}^{\prime}}$ \\
\hline-0.0025 & 0.003 \\
noise & noise \\
-0.0041 & 0.0014 \\
-0.0019 & 0.0007 \\
\hline
\end{tabular}




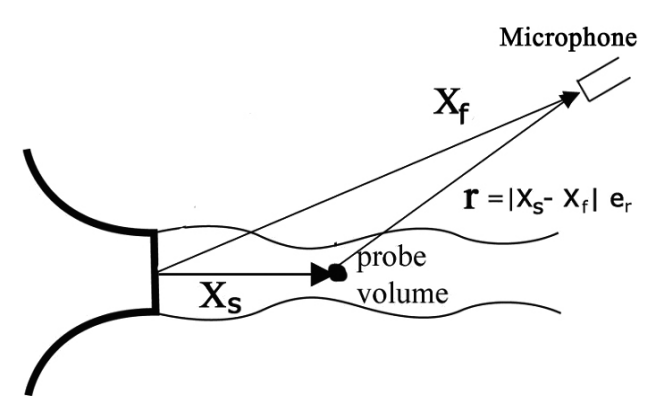

Figure 1.-Schematic of coordinate system and microphone locations.

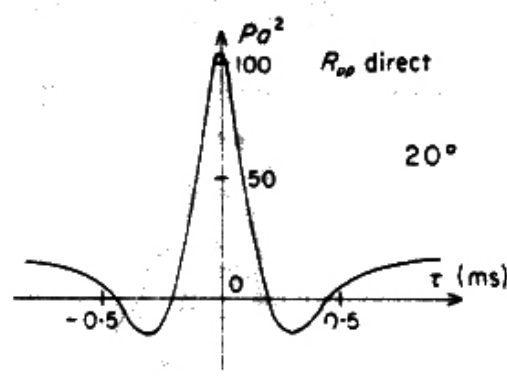

(a)

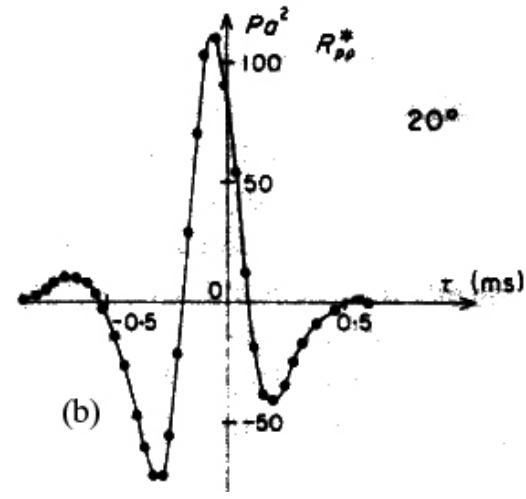

Figure 2.-Microphone auto-correlation in $\mathrm{Mj}=0.98$ jet (a) measured by a far field microphone at $\theta p=160^{\circ}$; (b) calculated by the application of the causality principle to the shear noise source $\left\langle\mathrm{u}^{\prime} ; \mathrm{p}^{\prime}\right\rangle$ measured from a large number of points in the plume. Plot from Schaffar $^{9}$ (1979).

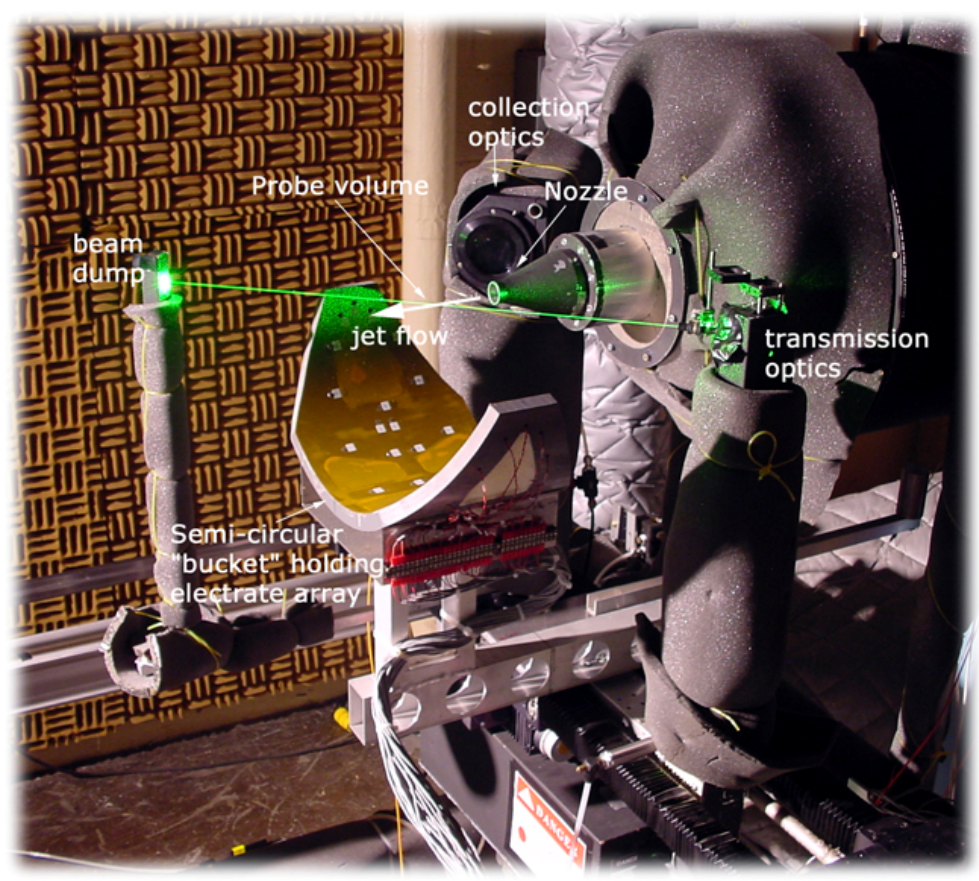

(a)

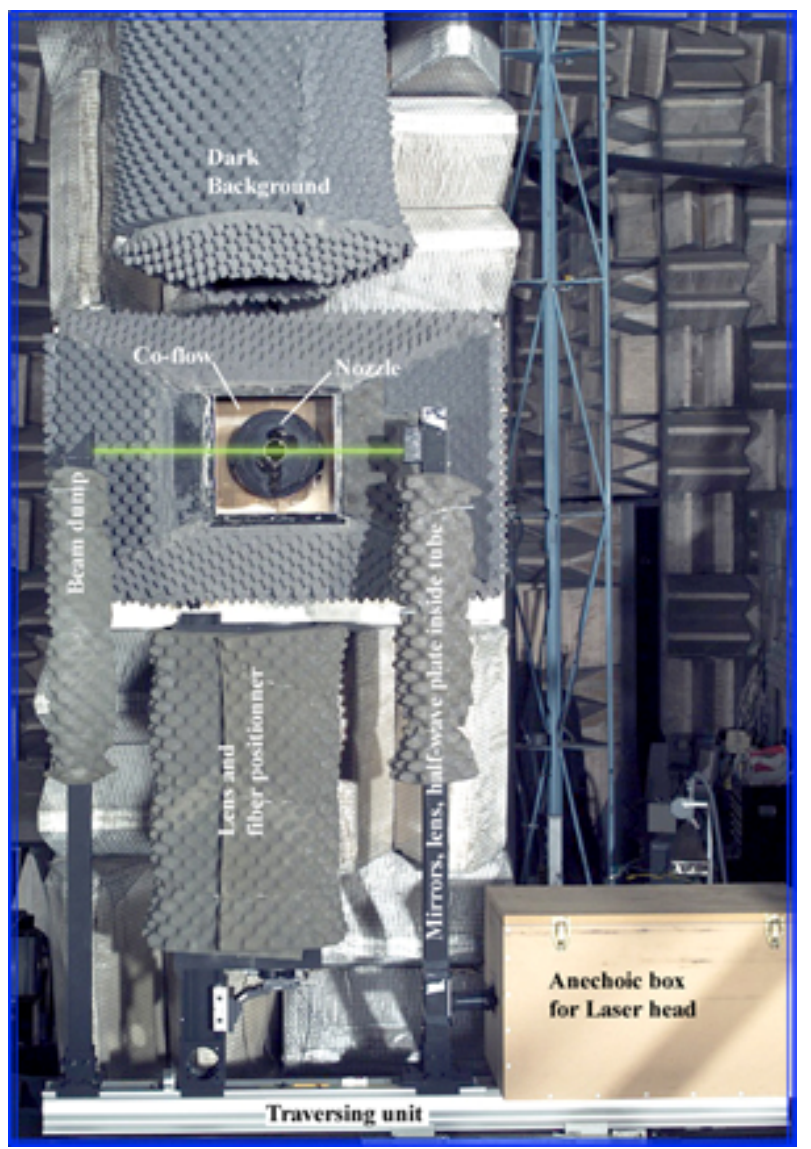

(b)

Figure 3.-Photographs of the jet facilities; (a) 1" unheated jets, (b) 2" heated jets. 

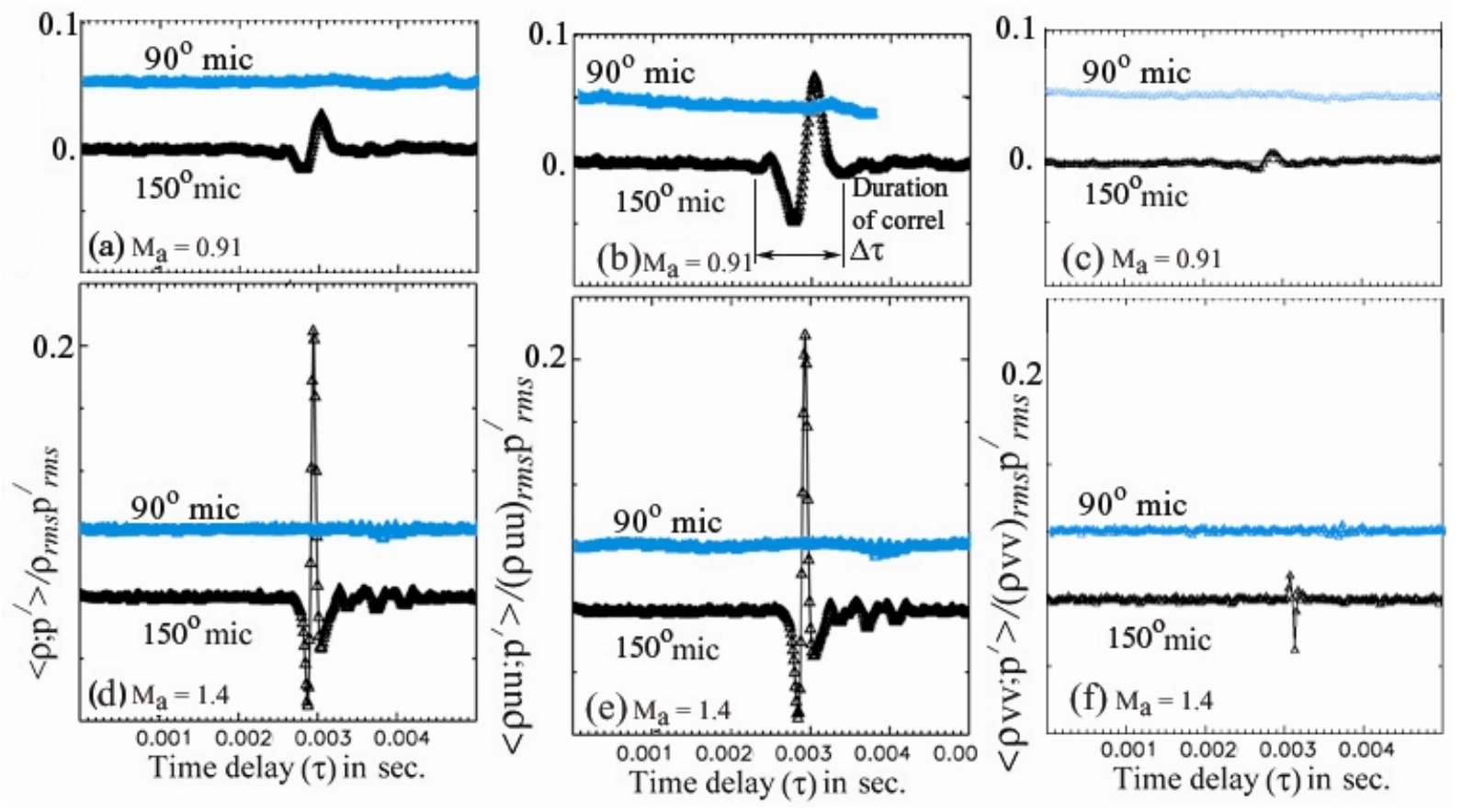

Figure 4.- Normalized cross-correlation between sound pressure fluctuations $\mathrm{p}^{\prime}$ and (a), (d) air density $\rho$; (b), (e) puu; (c), (f) $\rho v v$ fluctuations measured in $\mathrm{M}_{\mathrm{a}}=0.91$ and 1.4 jets. For (a), (b), and (c) laser probe was at $\mathrm{x} / \mathrm{D}=10$ and centerline; for $(d)$ and (e) probe is at $x / D=12$ and centerline; for (f) it is $x / D=6$ and $r / D=0.48$. The microphone was kept at 50D and at indicated polar angles. The $90^{\circ}$ microphone data are shifted by 0.05 . 


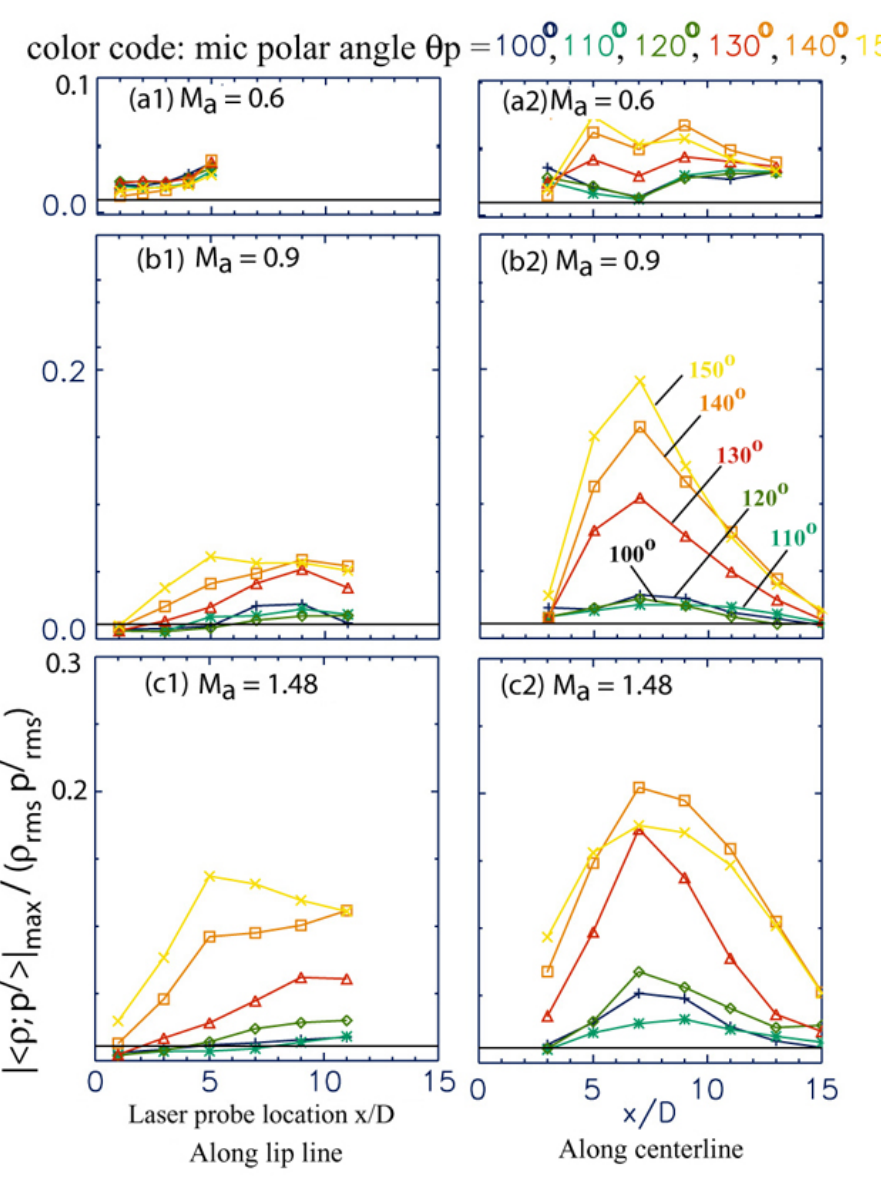

Figure 5.-Mach number (acoustic) and polar angle dependence of peak correlation coefficients. The laser probe was moved at different axial positions along (a1), (b1), (c1) lip line r/D = 0.5 and (a2), (b2), (c2) centerline $\mathrm{r} / \mathrm{D}=0$ of 3 different plumes of $\mathrm{M}_{\mathrm{a}}=0.6,0.9,1.48$ and respectively, $\mathrm{T}_{\mathrm{r}}=2.27,2.7,2.27$ jets. The different color plots are for different microphone polar angles as indicated in the color code. All microphones were kept on a 100D arc.

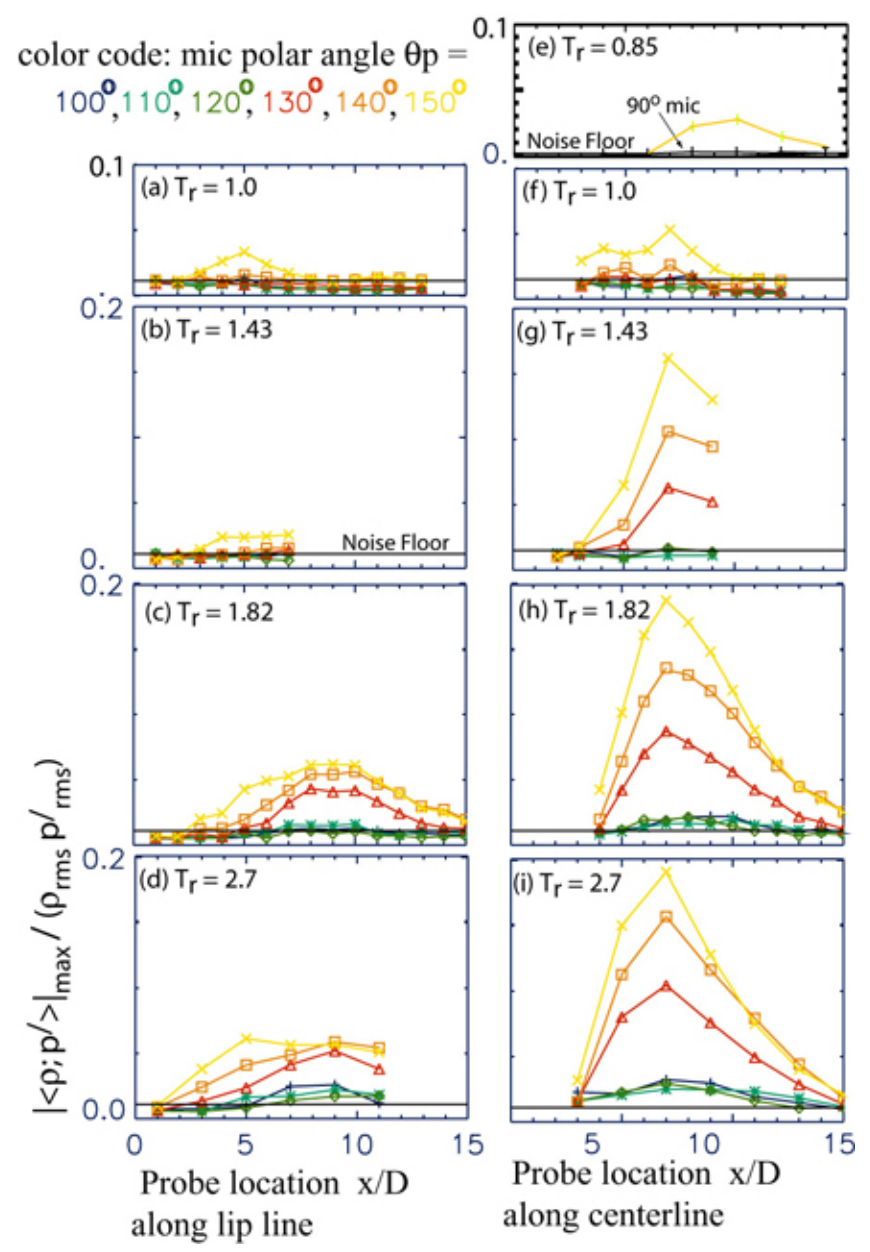

Figure 6.-Temperature dependence of the peak $<\rho$; $\mathrm{p}^{\prime}>$ correlation. $\mathrm{M}_{\mathrm{a}}=0.9$ and static temperature ratios $\mathrm{T}_{\mathrm{r}}$ are as indicated. For the left column plots laser probe was moved along lip line and for the right column, it was moved along the centerline. The different color plots are for different microphone polar angles as indicated in color code. All microphones were kept on a 100D arc. 


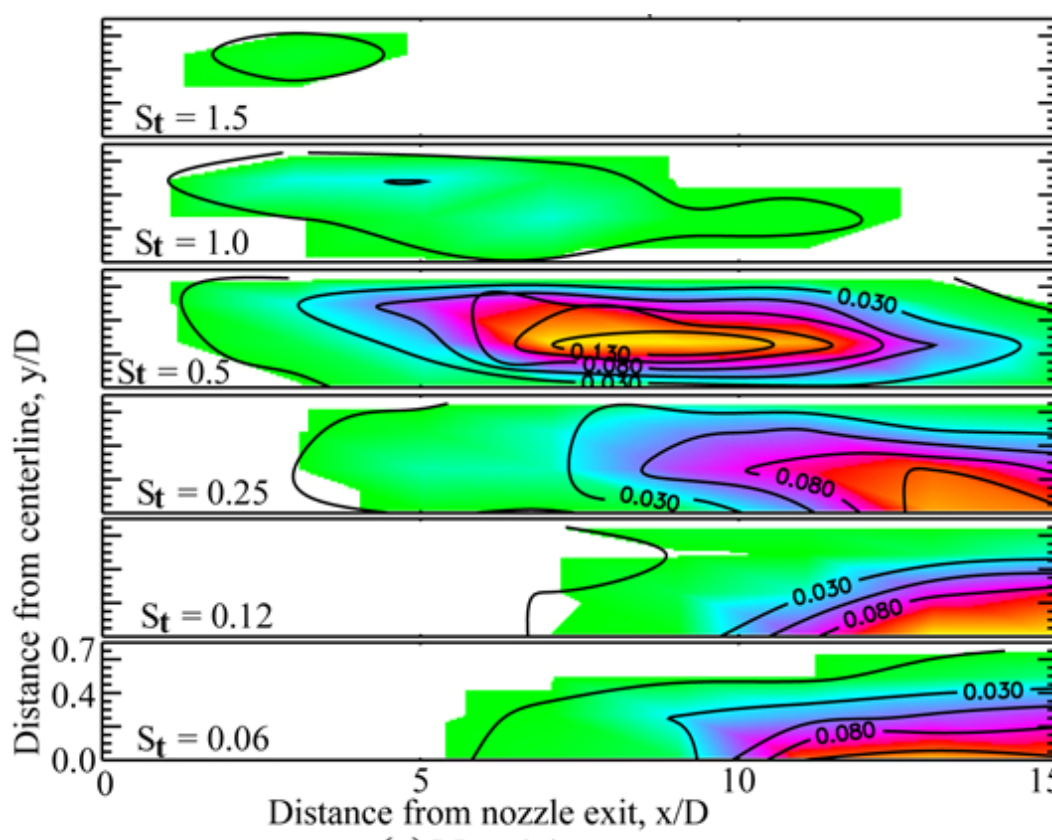

(a) $\mathrm{M}_{\mathrm{a}}=1.4$ coherence, $\Gamma^{2}$

0.105

0.055

0.005

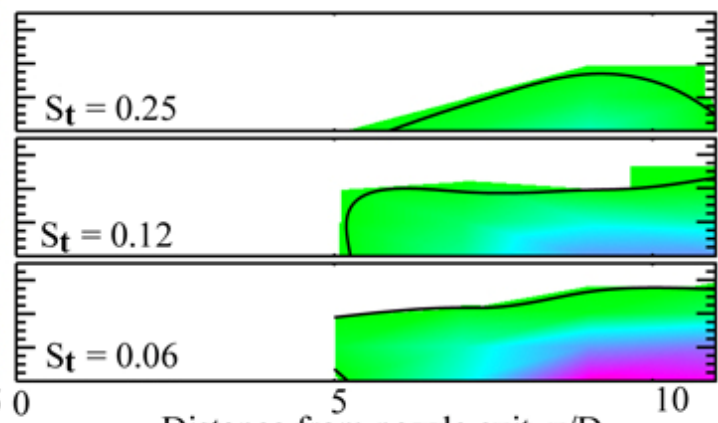

Distance from nozzle exit, $\mathrm{x} / \mathrm{D}$

(a) $\mathrm{M}_{\mathrm{a}}=0.91$

Figure 7.-Distribution of normalized cross-spectrum (coherence) between turbulent density fluctuations and far field sound pressure fluctuations at indicated Strouhal frequencies for two different unheated jets. The microphone was fixed at $\mathrm{r} / \mathrm{D}=50, \theta=150^{\circ}$ while the laser probe was moved from point to point.
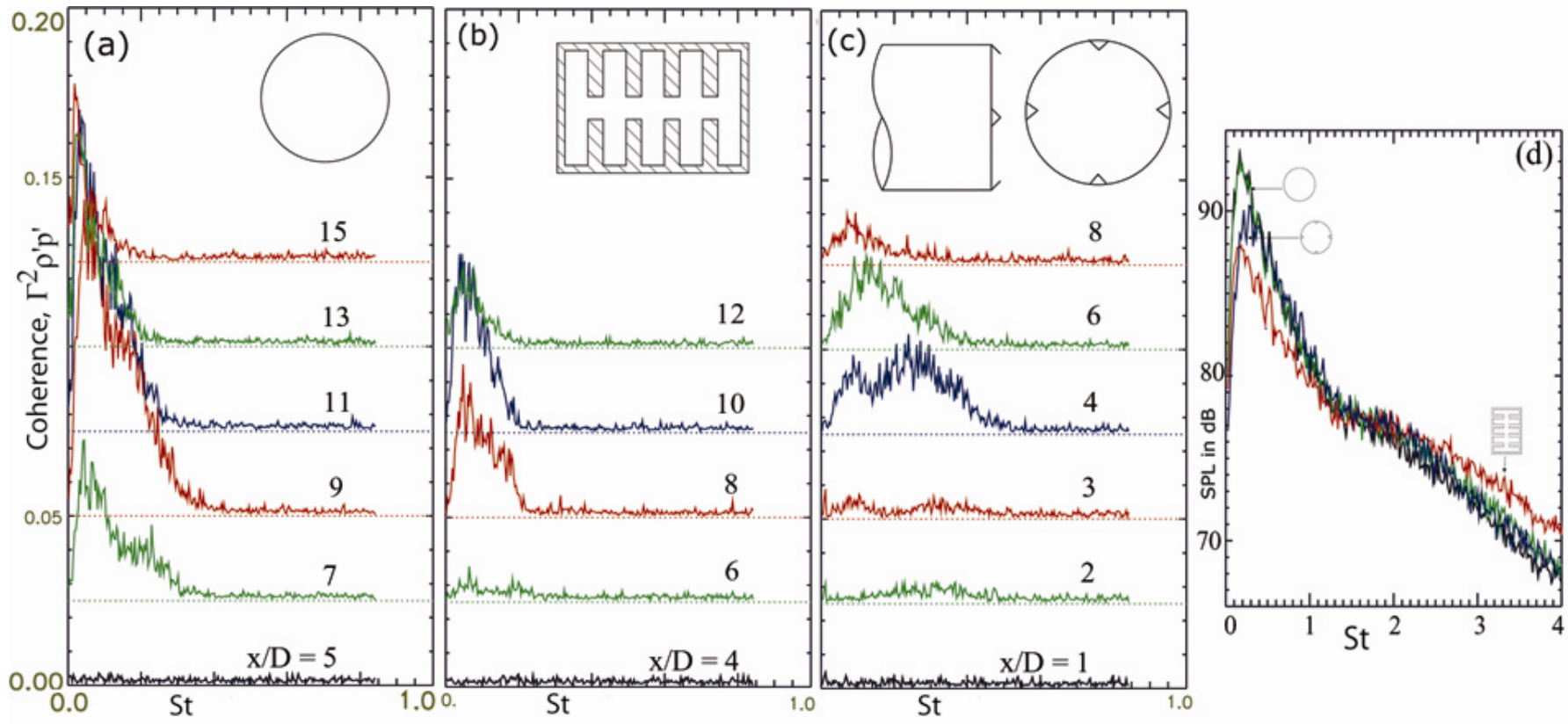

Figure 8.-Comparison of coherent spectrum between flow density and far field sound pressure fluctuations from 3 different nozzle configurations: (a) baseline circular, (b) 16 lobe rectangular and (c) 4-tab circular nozzles. Laser position was moved at indicated axial stations along centerline of unheated $\mathrm{M}_{\mathrm{a}}=0.91$ jet. Plots from different $\mathrm{x}$ positions are shifted by 0.025 . (d) Noise spectra from the fixed microphone at $x / D_{\text {eqv }}=50, \theta_{p}=150^{\circ}$. 


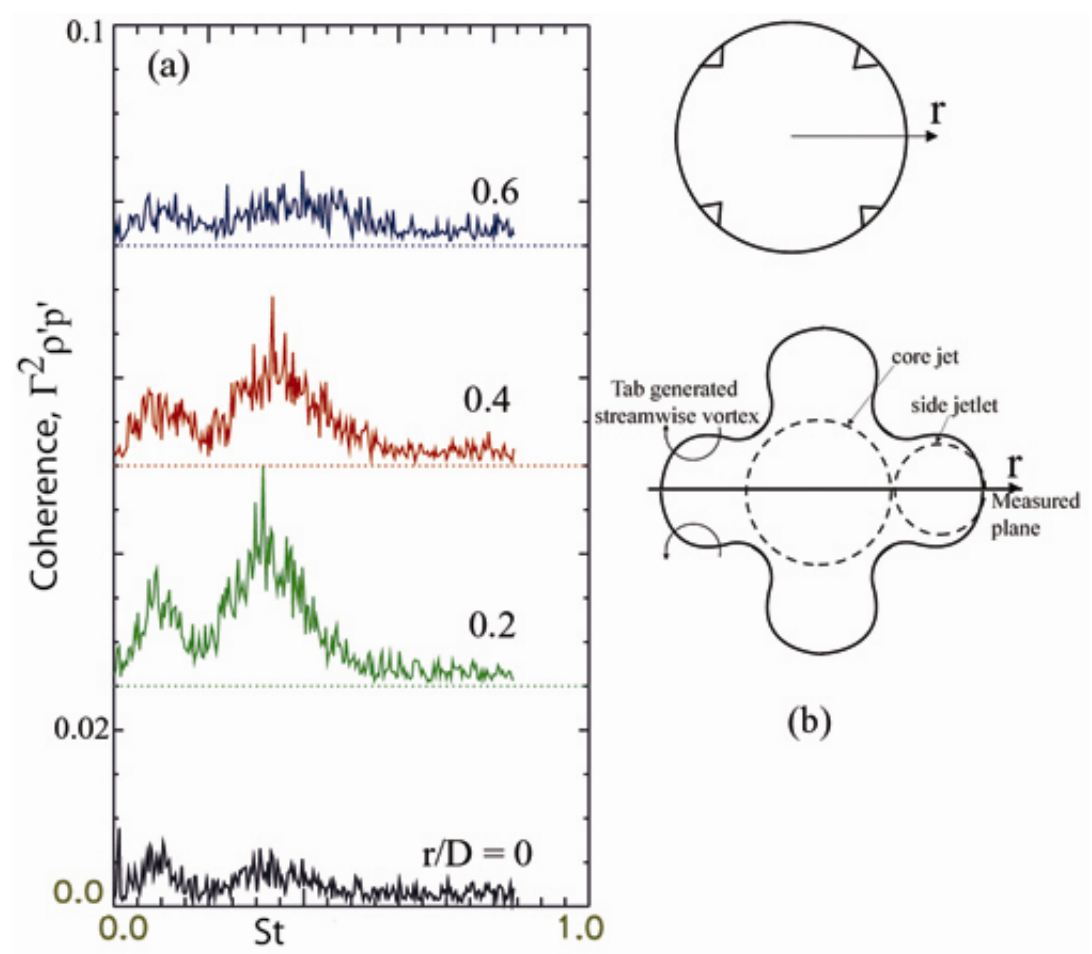

Figure 9.-(a) Coherence spectra between flow density fluctuations and far field sound pressure fluctuations in tabbed jet. The probe volume was moved radialy at indicated stations at fixed $x / \mathrm{D}_{\text {eqv }}=3$. The microphone was fixed at $x / D=50, \theta_{p}=150^{\circ}$. (b) Schematic of the flow field from 4 tabbed nozzle.
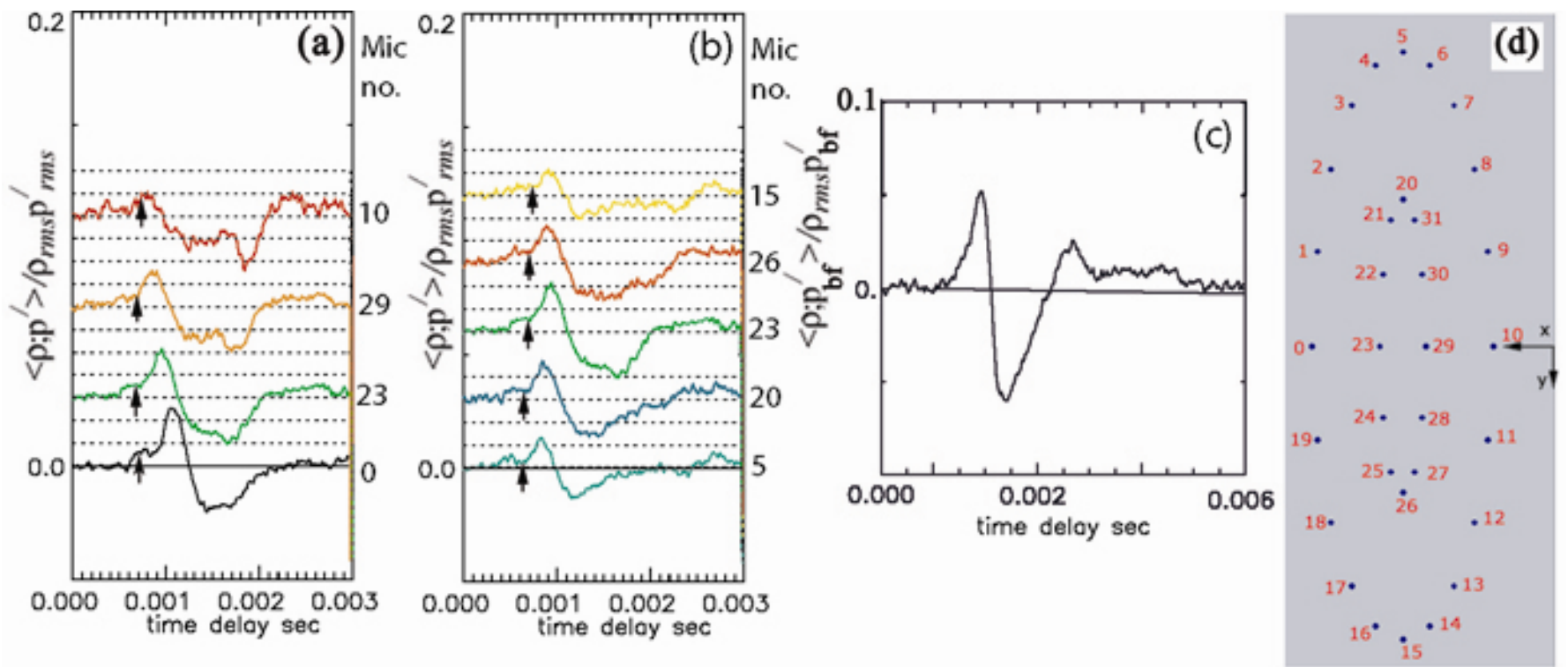

Figure 10.- Normalized correlation between air density fluctuations and (a), (b) selected individual microphones; (c) beam-formed signal created from all microphones. The laser probe was placed at $\mathrm{x} / \mathrm{D}=8, \mathrm{r} / \mathrm{D}=0$ in $\mathrm{M}_{\mathrm{a}}=$ 0.91 jet. (d) A "unwrapped" view of the phased array indicating microphone locations. Laser probe volume lies directly above the array center between microphones 23 and 29. The small arrows in parts (a) and (b) indicate free-space propagation time from probe volume to microphone. 

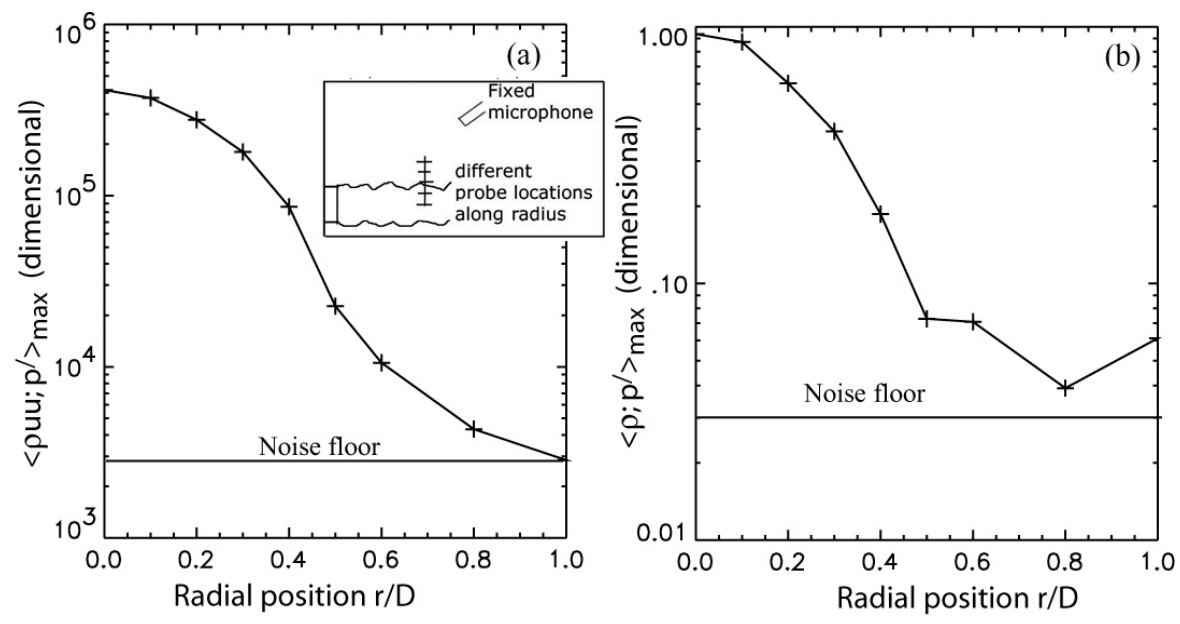

Figure 11.-Maximum value of correlation between sound fluctuations at fixed microphone $\left(\theta_{p}=150^{\circ}, R / D=50\right)$ and (a) puu and (b) $\rho$ fluctuations from various radial positions at $\mathrm{x} / \mathrm{D}=10$ inside unheated $\mathrm{M}_{\mathrm{a}}=1.18$ jet. Note that correlation values are not normalized.

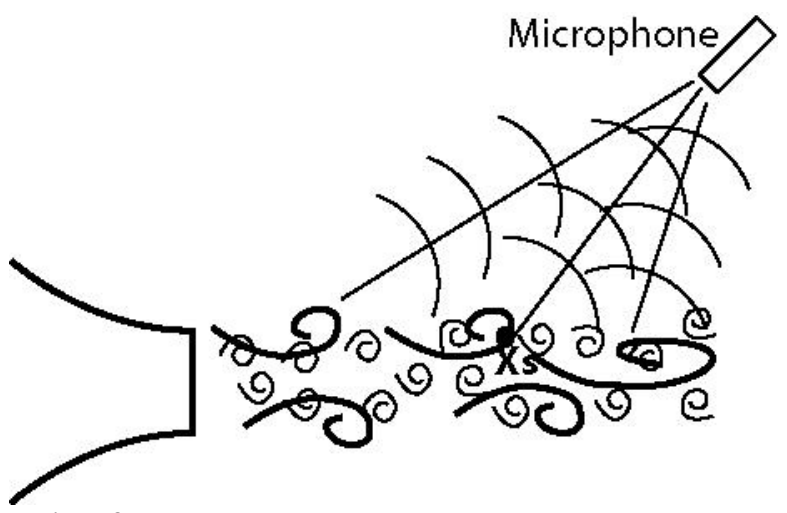

Figure 12.- Schematic of large and small scale turbulent structures and noise radiation. 


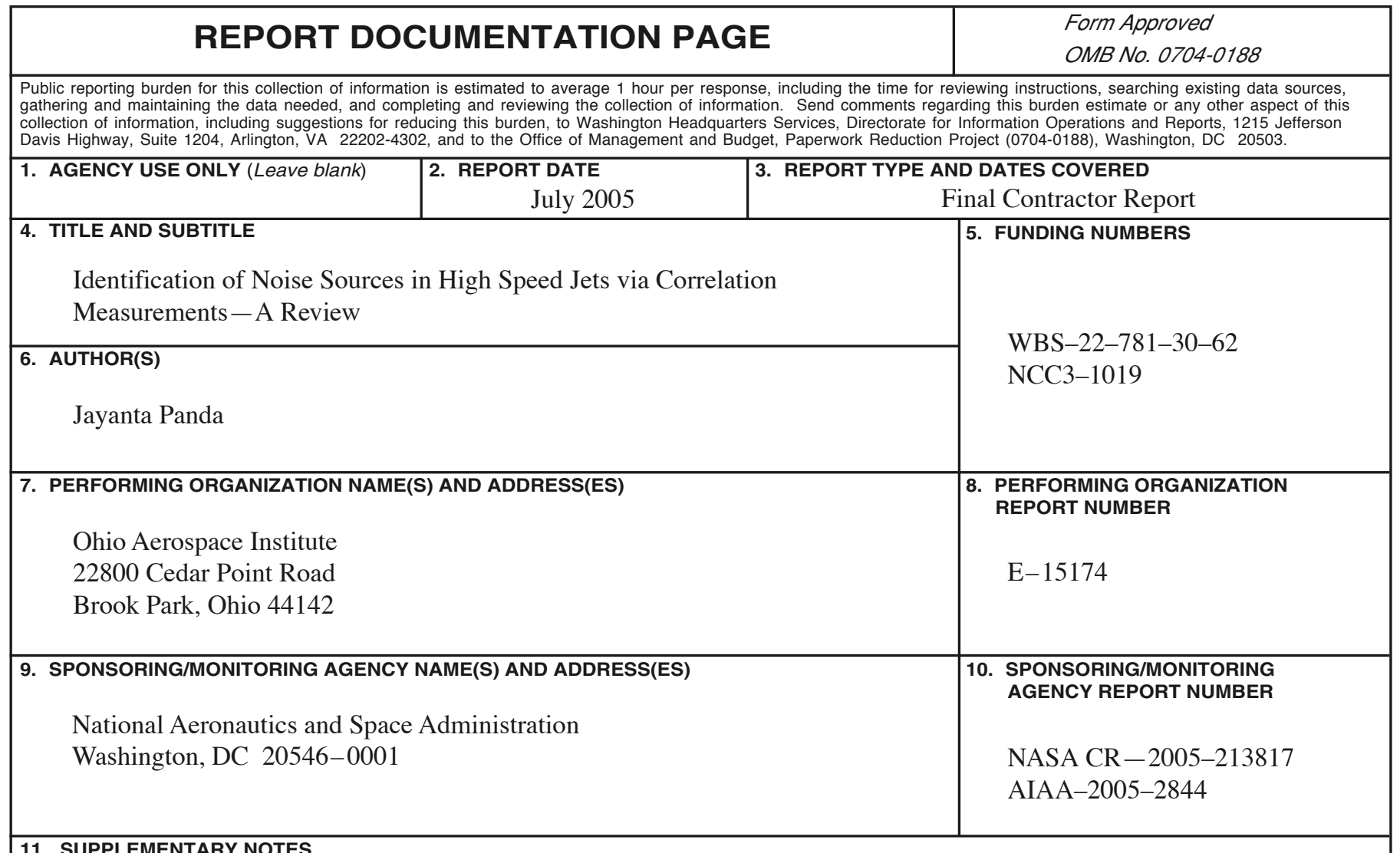

\section{SUPPLEMENTARY NOTES}

Prepared for the 11th Aeroacoustics Conference cosponsored by the American Institute of Aeronautics and Astronautics and the Confederation of European Aerospace Societies, Monterey, California, May 23-25, 2005. Project Manager, James Bridges, Propulsion Systems Division, NASA Glenn Research Center, organization code RTA, 216-433-2693.

\begin{tabular}{|l|l|}
\hline 12a. DISTRIBUTION/AVAILABILITY STATEMENT & 12b. DISTRIBUTION CODE
\end{tabular}

Unclassified - Unlimited

Subject Category: 45

Available electronically at http://gltrs.grc.nasa.gov

This publication is available from the NASA Center for AeroSpace Information, 301-621-0390.

13. ABSTRACT (Maximum 200 words)

Significant advancement has been made in the last few years to identify noise sources in high speed jets via direct correlation measurements. In this technique turbulent fluctuations in the flow are correlated with far field acoustics signatures. In the 1970's there was a surge of work using mostly intrusive probes, and a few using Laser Doppler Velocimetry, to measure turbulent fluctuations. The later experiments established "shear noise" as the primary source for the shallow angle noise. Various interpretations and criticisms from this time are described in the review. Recent progress in the molecular Rayleigh scattering based technique has provided a completely non-intrusive means of measuring density and velocity fluctuations. This has brought a renewed interest on correlation measurements. We have performed five different sets of experiments in single stream jets of different Mach number, temperature ratio and nozzle configurations. The present paper tries to summarize the correlation data from these works.

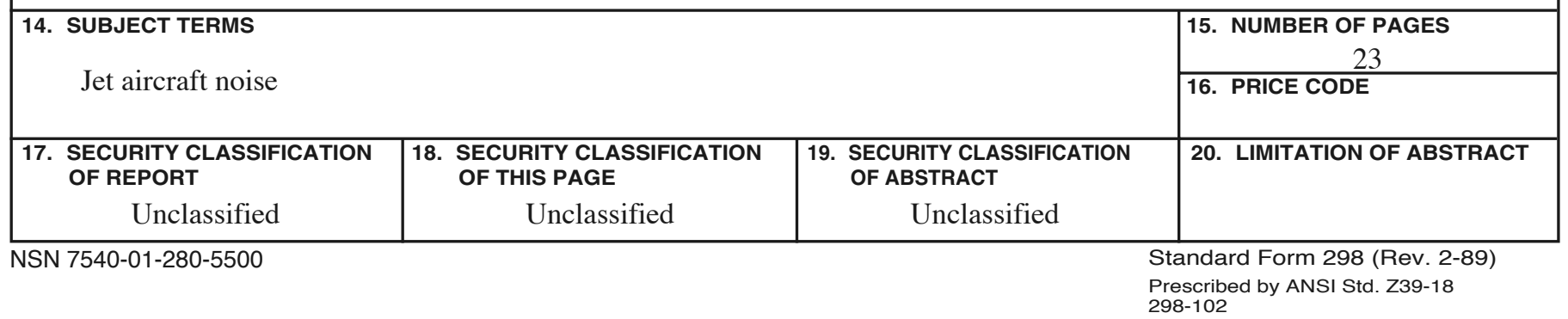



